\title{
THRUST CONTROL SYSTEMS OF PROPULSION AND THEIR VERIFICATION ON DYNAMICALLY POSITIONED VESSELS
}

\author{
Jerzy Herdzik \\ Gdynia Maritime University, Marine Power Plant Department \\ Morska Street 81-87, 81-225 Gdynia, Poland \\ tel.: +48585586430,fax: +48585586399 \\ e-mail:j.herdzik@wm.umg.edu.pl
}

\begin{abstract}
Thrust vector control systems of propulsion systems of dynamic positioning vessels are commonly applied on vessels with DP2 and DP3 class of DP. It was submitted the ways of providing information to dynamic positioning operator DPO about detecting of suspicion of failure in specific thruster and shown the ways of response in such situations. In the case of failure and shut down one of working thrusters, it must be done the possibility assessment of continuation of DP system safe operation. If such situation is not possible, it should be considered the work of DP system on limitations. It was indicated on safety threats during operation of DP systems resulting from system failure or even the design faults. It commonly applies the failure mode and effect analysis (FMEA or FMECA) from the design phase through sea trials until to the verification process during operation. It allows the elimination of majority of faults in the DP systems. It was communicated the basic conditions of safe operation of vessels with DP systems and the examples of conditions which releasing the readiness signal of DP propulsion system elements. Observed development of control and automatics systems will result in increasing the safety of DP systems operation.
\end{abstract}

Keywords: vessel, thrust, thrust control, DP system

\section{Introduction}

The first dynamic positioning systems emerged in 1960's as conventional mooring systems for offshore units of oil and gas industry. Dynamic positioning is a way to ensure the proper heading and speed of a vessel or position and hull orientation exclusively by means of propulsion systems (thrusters forces) working in allowable loads [2, 17]. DP vessels are equipped in complex propulsion systems giving the possibility of automatic control and steering of a vessel according to the class of DP $[2,4,7,10]$. The environmental and external forces affecting on vessel hull and disturbing to provide vessel functions should be compensated by thrust distribution from propulsion system. Apart from positioning the DP system can also take other aspects into account, such minimizing the power consumption (also total fuel consumption), forbidden/spoil zones of thrusters and thruster relations.

An example of propulsion system for pipe-layer vessel with class DP2 is presented in Fig. 1.

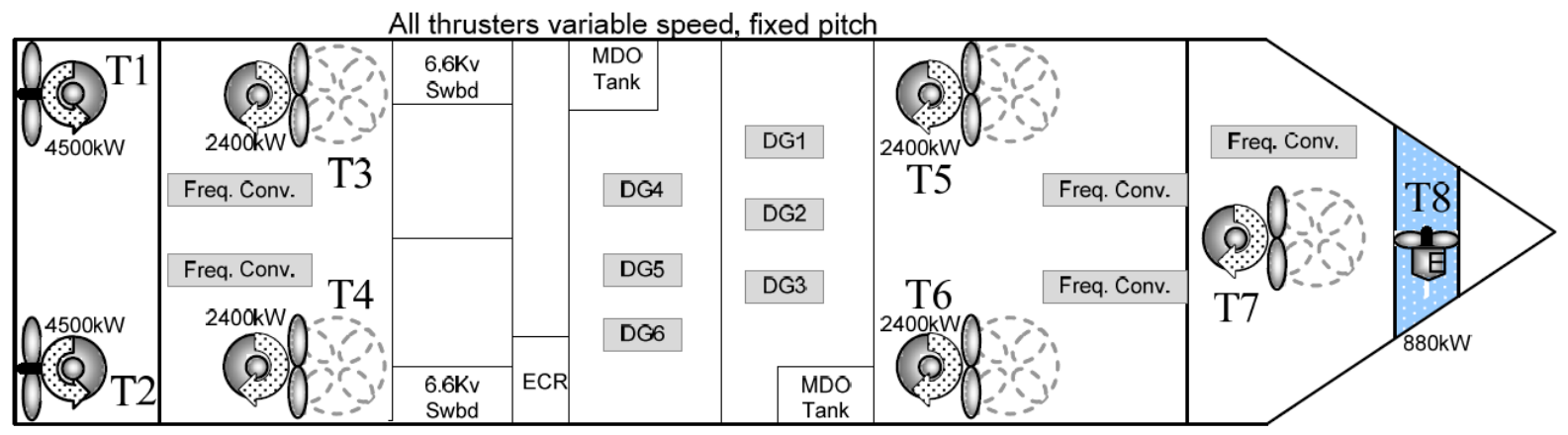

Fig. 1. Propulsion system of a pipe-layer vessel mv Global 1200 [1] 
Global 1200 are equipped in seven azimuth thrusters having fixed pitch, working with variable rotational speed and a bow tunnel thruster. Total propulsion system power is $21.880 \mathrm{~kW}$. The collation of position, power, and types of thrusters are presented in Tab. 1.

Tab. 1. Position, power, and type of thruster on a vessel Global 1200 (key component to Fig. 1) [1]

\begin{tabular}{|c|c|c|c|c|c|}
\hline $\begin{array}{c}\text { number } \\
\text { of thruster }\end{array}$ & $\begin{array}{c}\text { type and position } \\
\text { of thruster }\end{array}$ & $\begin{array}{c}\text { pitch } \\
\text { of thruster }\end{array}$ & speed & manufacture, type & thruster propulsion \\
\hline T1 & main, azimuth PS & fixed pitch & variable & $\begin{array}{c}\text { Wartsila } \\
\text { FS3500NU }\end{array}$ & $\begin{array}{c}\text { electric motor } 4.5 \mathrm{MW} \\
\text { Converteam MV7000 }\end{array}$ \\
\hline T2 & main, azimuth SBS & fixed pitch & variable & as above & as above \\
\hline T3 & stern, azimuth PS & fixed pitch & variable & $\begin{array}{c}\text { Wartsila } \\
\text { FS1510/1530MNR }\end{array}$ & $\begin{array}{c}\text { electric motor } 2.4 \mathrm{MW} \\
\text { Converteam MV3000 }\end{array}$ \\
\hline T4 & stern, azimuth SBS & fixed pitch & variable & as above & as above \\
\hline T5 & bow, azimuth PS & fixed pitch & variable & as above & as above \\
\hline T6 & bow, azimuth SBS & fixed pitch & variable & as above & as above \\
\hline T7 & bow, azimuth & fixed pitch & variable & as above & as above \\
\hline T8 & bow, tunnel thruster & fixed pitch & variable & $\begin{array}{c}\text { Wartsila } \\
\text { FT175M-D }\end{array}$ & $\begin{array}{c}\text { electric motor } 880 \mathrm{~kW} \\
\text { Converteam MV3000 }\end{array}$ \\
\hline
\end{tabular}

Stern thrusters T1, T2 and tunnel thruster T8 are used at sea voyage to assure the proper vessel speed and total efficiency of propulsion (from a port to a place of work). There is a possibility of all thrusters on loads during vessel dynamic positioning. The steering signal allows distributing the proper thrust and position of each thruster for reach the resultant force and momentum to compensate the influence of external/environmental changes and forced the vessel motion or positioning in relation to seabed or other vessel according to the intention of dynamic positioning operator (DPO). The proper propulsion system work and all elements of DP system are verified in design phase and during trials at sea. The failure mode and effect analysis (FMEA) is used to a verification process. FMEA checks the correctness of design process, signal flow identification among elements of DP system and the effects for DP system during emergency situations or failures.

Verification concerns to following systems $[12,13,15]$ :

- DP control system,

- steering and control system of thrusters with control of position and thrust of each one,

- system of electric energy production, distribution system and control, steering and adjustment systems,

- auxiliary systems like: measure system of imposed forces and momenta affecting on vessel hull, direction and strength of wind, hull dynamics, vessel position measuring systems,

- alarm systems, DP danger and failure detection system.

An example of auxiliary system arrangement of azimuth thruster is presenting in Fig. 2.

\section{Thruster control system}

DP system is the most sophisticated steering and control system of vessel's propulsion. DP system divides calculated forces among vessel's thrusters, which make the required force and direction of thrust.

The main function of Thruster Control System (TCS) (presented in Fig. 3) is actively control the direction and force from all thrusters to achieve needed position/heading of the vessel given the by DPO command (manual control mode) or from an external Autopilot or DP system command (automatic control mode). 


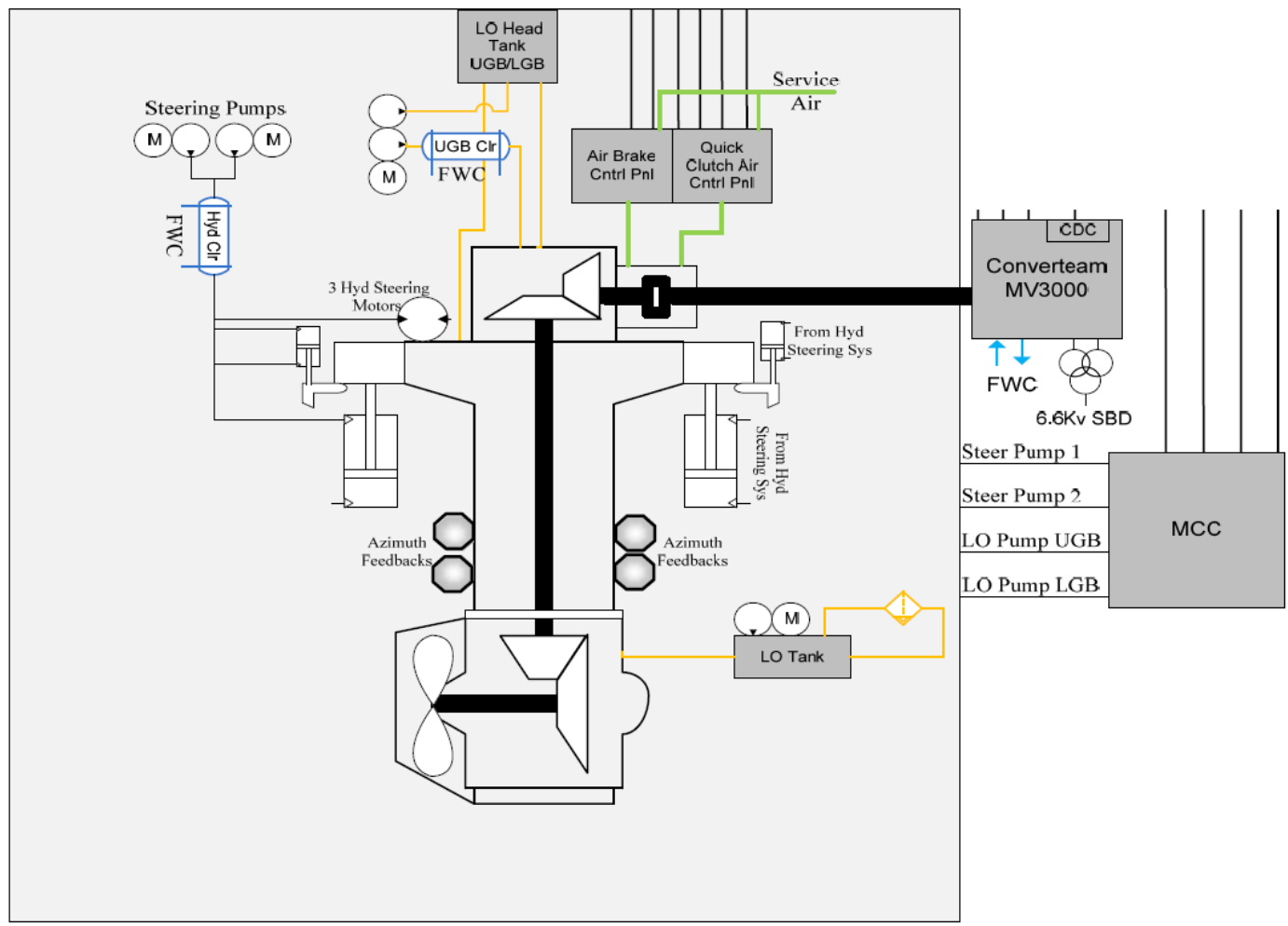

Fig. 2. An arrangement of azimuth thruster auxiliary system [1,5]

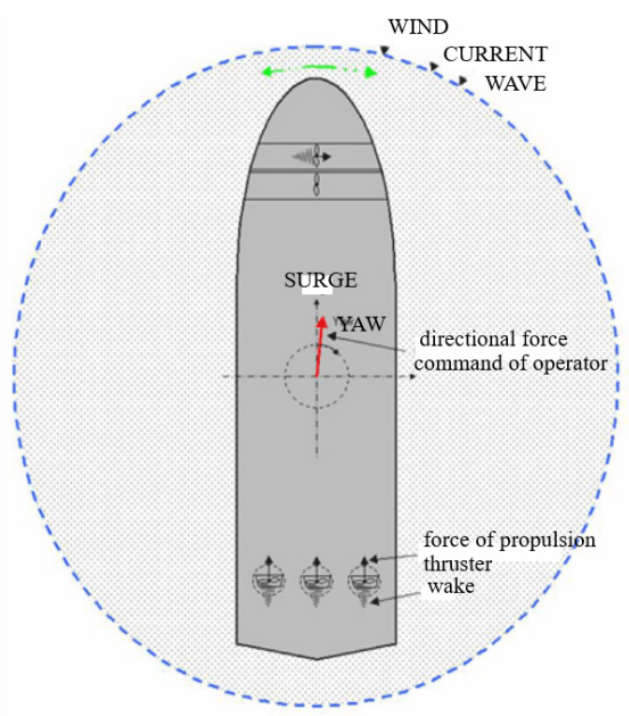

Fig. 3. Thruster Control System in manual control mode [on a base of 16]

TCS is built around on advanced control algorithm [1, 3, 14]. Vessel dynamics (determined as mathematical model) are computed the theoretical thrust necessary to counteract external forces and disturbances. It is required additional correction algorithm to prevent any deviation from desired vessel heading, speed, or position. Reference systems determine the deviation in vessel heading [Siemens], whilst sensors are used to determine environmental strength and direction. The needed thrust is generated upon predicted vessel behaviour.

The Thruster Control System controls the vessel's motion in three degrees of freedom - surge, sway and yaw (from possible six degrees of freedom) is normally an integrated part of overall control system. The compensation of the fourth degree of freedom (heave) is prepared only for specialized equipment (e.g. drilling system) which is a part inside the hull of vessel but fastened on tensioners. 
The main operating modes and features of the system can be summarized as follows: operator selection between DP, Joystick, Manual Levers and Autopilot Modes (see Fig. 4).

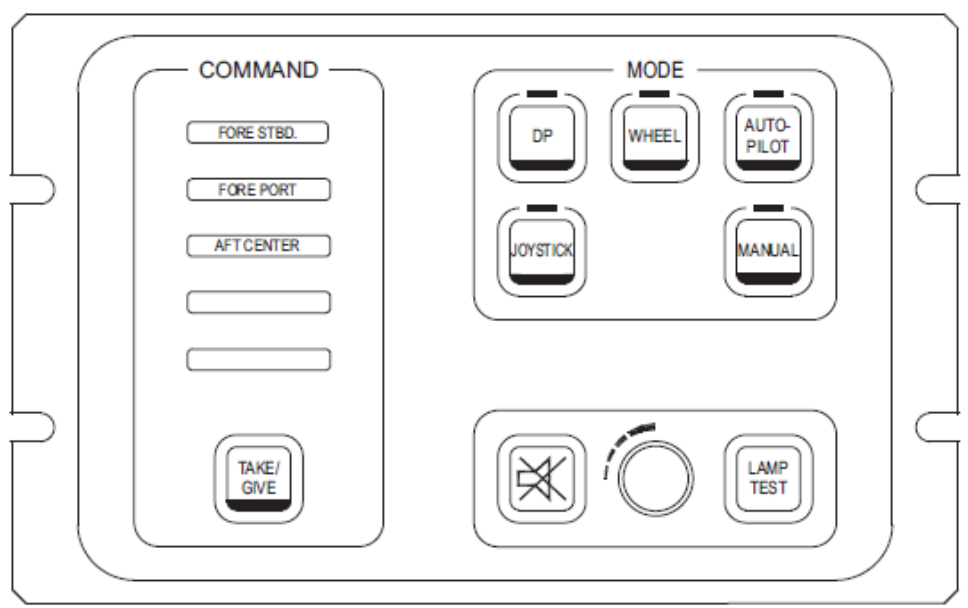

Fig. 4. The main operating modes of propulsion system steering - steering panel [1]

Joystick Mode has the following functionality [6, 14]:

- automatic control of heading and direction;

- thrust compensation based on wind, current and wave calculation;

- possible operation of a combination of variable and fixed thruster azimuth;

- three possible gain settings for the joystick;

- automatic thrust compensation in the event of start-up or shutdown of thrusters. Manual Lever Mode has the following functionality:

- control of each thruster (azimuth and propeller speed or propeller pitch);

- run-in-mode;

- sequential start-up of thrusters;

- Manual Operation of thruster equipment for service and test purposes;

- possibility for entry of forbidden zones for each thruster (prohibition of work inside forbidden zone).

\section{Necessity of thrust control from all thrusters}

The control of acting correctness all DP equipment is the base of emergency event preventing. The failure of steering, control and power system and should be detected [3]. Detection of failure in DP system allows to shut down the defective equipment or to ignore the signals from that one. Due to installed redundancy, the DP system may be farther full operational. Suspect equipment after verification process (many times after restart) should be back to work in DP system [5-7].

The shutdown or disconnection of thruster from DP system may be done by many methods:

- thruster separation from steering signals from DP system (omission),

- clutch disconnection in mechanical propulsion system equipped in fixed pitch propeller,

- adjustment on zero pitch of controllable pitch propeller, it allows to minimize the thrust from thruster to about zero - the thruster is in standby mode, after verification of proper work may bring back to work as a part of DP system,

- electric motor switching off a thruster in diesel-electric systems.

The thruster control panel is presented in Fig. 5.

The azimuth thrusters may produce the oriented thrust in $360^{\circ}$ around its own axis (if no sector limits). The thruster failure may be detected as non-conformity between the set and real direction of thrust $[8,9]$. The feedback about parameters of all thruster work is required. An example of thruster parameters panel is presented in Fig. 6 (portside thruster no. 2). 


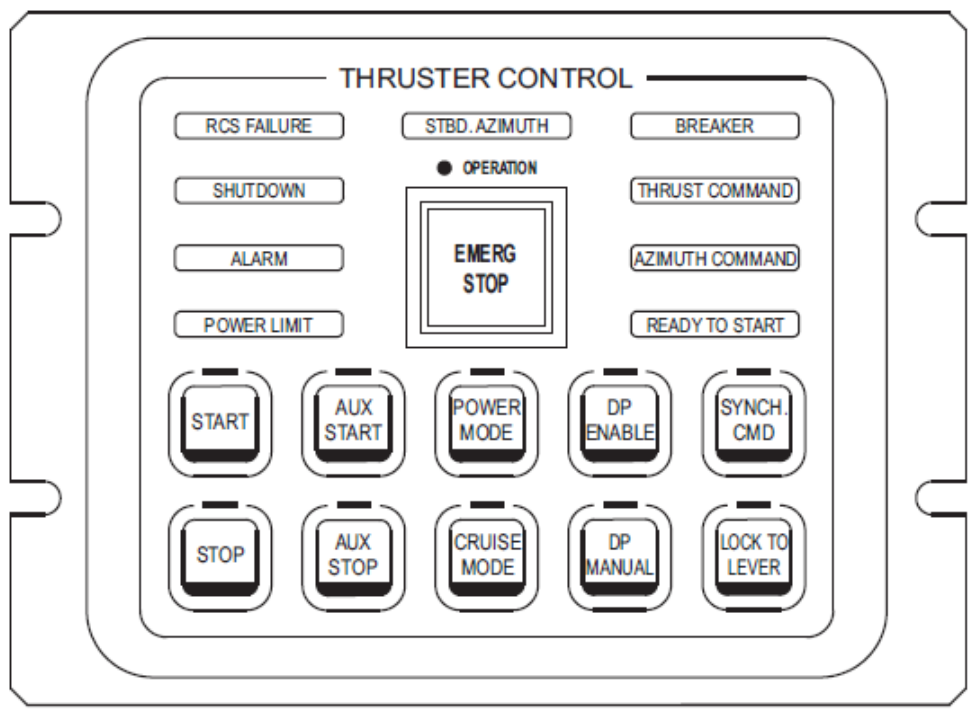

Fig. 5. Thruster Control Panel [1]

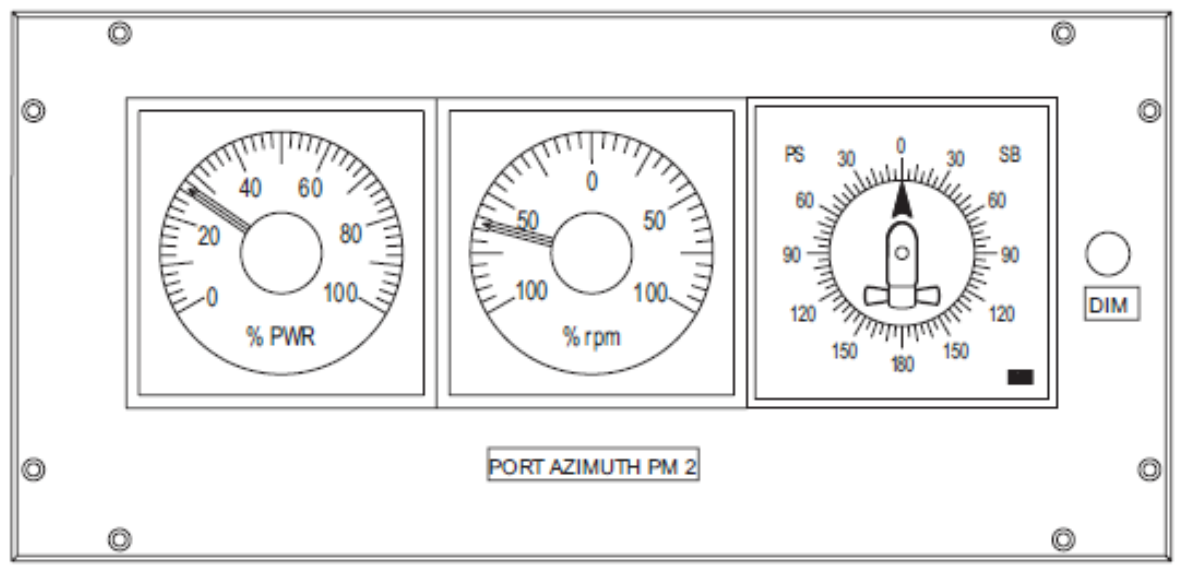

Fig. 6. The essential work indicators of a thruster: from left side: the percentage of nominal power indicator, the percentage of nominal speed, the direction of thrust in comparison to main vessel axis [1]

In some cases it is a necessary the limitations of thruster angle rotation or thrust limits, which the thruster may potentially produce. In multi-thrusters propulsion, systems it is possible such situation that the chosen thruster works only in attached sector e.g. the thrust vector has limited angles of work (see Fig. 7). It allows on quicker reaction of thruster (due to shorter time of rotation because the angle of position change is smaller) and the failure detection or a risk of automatic switching off in case of entrance in prohibited sector (crash stop).

The essential conditions of safe vessels operation with dynamic positioning systems are determined (presented in Tab. 2). The majority of conditions are enough evident. Their fulfilment is a base of operation of a vessel and its all energetic-propulsion systems in all expected operation states. Due to DP systems specificity, construction and equipment specificity of a particular vessel it may occur essential differences, which have an influence on safe operation of above-mentioned systems. The conditions are determined after the testing of fault monitoring and effect analysis (FMEA or FMECA). Prepared procedures should simplify vessel's crew the fulfilment of all requirements and reduce the number of faults made by crew (human factor) [11]. The complexity of DP systems is so incredibly large that it is possible to do a simply fault having strong effects on a vessel safety. It is determined what effects (states, parameters, alarms) should result in the tested failure, is it important for proper work of DP systems, what additional actions should be done by DP operator for limiting the effect of such failure. Of course in theory, because in a practice it carries many difficulties. It is a necessary of DP systems to the ability for self-diagnostics e.g. after 
occurring the determined states, alarms or parameters beyond limits the control system should inform the DP operator about the failures and what should be done for bringing back the system to healthy state $[8,12]$.

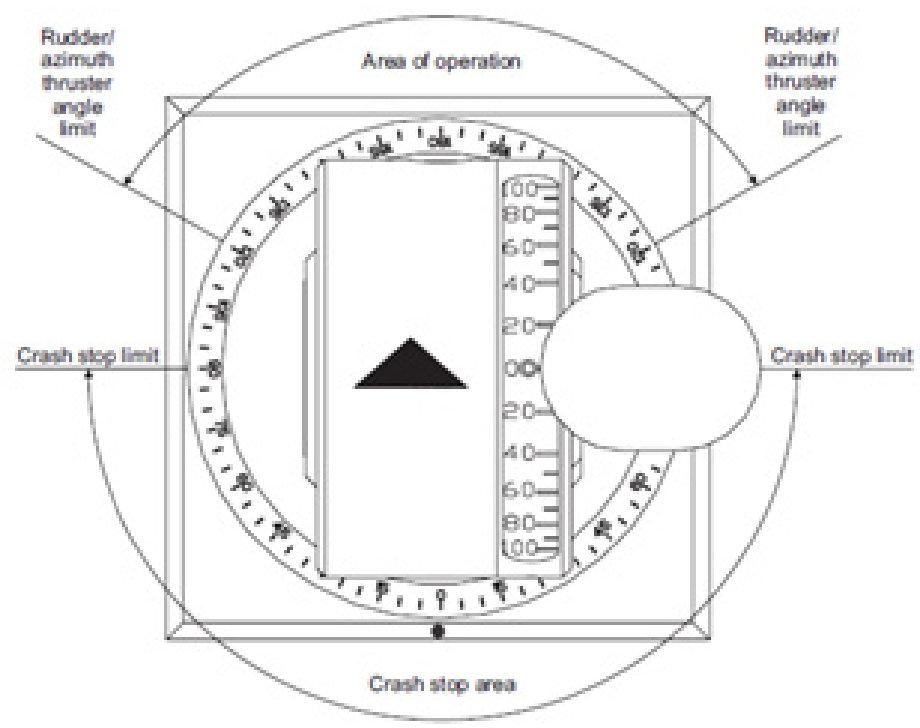

Fig. 7. The limitations of thruster angle rotation (area of operation) or thrust limits [1]

Tab. 2. The essential conditions of safe vessel operation with DP systems [1]

\begin{tabular}{|c|l|}
\hline $\begin{array}{c}\text { System } \\
\text { DP (dynamic } \\
\text { positioning) }\end{array}$ & $\begin{array}{l}\text { All system sensors control computers, workstations, Ethernets and thrusters healthy } \\
\text { and selected. Minimum of two independent position reference sensors selected. }\end{array}$ \\
\hline $\begin{array}{c}\text { IJS (independent } \\
\text { joysticks) }\end{array}$ & Healthy and ready. \\
\hline $\begin{array}{c}\text { thrusters } \\
\text { propulsion) }\end{array}$ & $\begin{array}{l}\text { All thrusters running and healthy. All support services engaged. Sufficient thrusters } \\
\text { selected to maintain redundancy in the available operating environment. Details in } \\
\text { DP Ops Manual. }\end{array}$ \\
\hline $6,6 \mathrm{kV}$ voltage & $\begin{array}{l}\text { Split bus, and DC control power to each side of the bus fed from different battery } \\
\text { chargers. }\end{array}$ \\
\hline $\begin{array}{c}\text { 480V voltage } \\
\text { 120/240V voltage }\end{array}$ & $\begin{array}{l}\text { Switchboards split and fed from their transformers. Emergency generator ready to } \\
\text { start. No ground faults. }\end{array}$ \\
\hline BPS/DC Power & Batteries chen and buses fed from their transformers. No ground faults. \\
\hline $\begin{array}{c}\text { VMS/PMS } \\
\text { power or energy } \\
\text { management) }\end{array}$ & Converteam operator stations and field stations healthy and ready. \\
\hline fuel & Operate split, sample, settle, purify, stagger filling to allow detection of problems. \\
\hline lubricating oil & Maintain pipes, sample and purify. \\
\hline cooling & $\begin{array}{l}\text { Maintain pipes, connections and coolers, no heavy lifts or hot work near common } \\
\text { fresh water coolers or sea water coolers piping during DP2 operations. }\end{array}$ \\
\hline $\begin{array}{c}\text { emergency } \\
\text { switch board }\end{array}$ & All power sources ready with no wire break alarms. \\
\hline $\begin{array}{c}\text { HVAC (heating, } \\
\text { ventilation } \\
\text { and cooling) }\end{array}$ & Running and effective. \\
\hline $\begin{array}{c}\text { environment } \\
\text { external conditions) }\end{array}$ & Operate within worst-case environment envelope (conditions). \\
\hline $\begin{array}{c}\text { maintenance } \\
\text { fegular maintenance and testing in accordance to manufacturer's recommendations }\end{array}$ \\
\hline
\end{tabular}


DP system correctness control is held in the real time but information about its state is relayed in simplified way as a beacon of a lamp in following colours:

- green - informs that system is healthy; all working equipment parameters are in admissible limits,

- yellow - informs about the failure states, in result the available power from thrusters are limited,

- blue - means that DP system works in other steering modes (outside DP) e.g. manual,

- red - informs that the work of DP systems is impossible, requires the reaction of DP operator and undertaking the corrected actions,

- flashing lamp - means transient states, the DP operator should undertake a decision about the change of steering or control mode of energetic or propulsion systems [13].

\section{An example of readiness signalization the DP systems for work}

DP system operator should have reliable (sure) information about the readiness of DP system for work. The readiness signals for work from all thrusters support him. Examples of conditions, which they trigger, the readiness signals are presented in Tab. 3 and Tab. 4.

Tab. 3. An example of conditions, triggering the readiness signal of bow thruster for work

\begin{tabular}{|c|c|c|c|}
\hline \multicolumn{4}{|c|}{ Conditions triggering the signal of readiness for work the bow thruster of DP system } \\
\hline & Type & Description & Remarks \\
\hline- & DI & Booster pump work & Should work only 1 pump \\
\hline n/a & SOW & System ... ready & DP mode available \\
\hline n/a & SOW & Control module of thruster pitch healthy & No signal of fault \\
\hline- & DI & Bow thruster engine on & $\begin{array}{c}\text { Pitch signal of thruster } \\
\text { in admissible range }\end{array}$ \\
\hline- & DI & Bow thruster engine in remote control mode \\
\hline- & SOW & $\begin{array}{c}\text { Feedback of thruster pitch is correct } \\
\text { (turning signal) }\end{array}$ & \\
\hline
\end{tabular}

n/a - not applicable, DI - direct information, SOW - state of work

Tab. 4. An example of conditions, triggering the readiness signal of DP propulsion system for work

\begin{tabular}{|c|c|c|c|}
\hline \multicolumn{3}{|c|}{ Signal of thruster readiness ... DP system } \\
\hline & Type & Description & Remarks \\
\hline- & DI & Gearbox pump work & Should work only 1 pump \\
\hline n/a & SOW & System ... ready & DP mode available \\
\hline n/a & SOW & Control module of thruster pitch healthy & No signal of fault \\
\hline- & DI & Bow thruster engine on & \\
\hline- & DI & Thruster engine in remote control mode & \\
\hline- & DI & Thruster in remote control mode & \\
\hline- & SOW & Feedback signal layout 1 - OK & Signal in admissible range \\
\hline- & SOW & Feedback signal layout 2 - OK & Signal in admissible range \\
\hline
\end{tabular}

$\mathrm{n} / \mathrm{a}$ - not applicable, DI - direct information, SOW - state of work

The software upgrade is the most important matter for DP systems still increasing the importance. The software is constantly improving but it is finding new holes which resulting unforeseeable occurrences, many times dangerous to safety of vessel and crew $[9,11,12]$.

\section{Final remarks}

Redundancy has made DP systems more reliable. The growing demand for more fuel-efficient operation (to minimize the total power of thrusters) and the need for more advanced control over 
the thrusters, calls for the development of new control techniques.

DP systems are full-fledged steering and control systems supporting DP operator decision significantly simplifying his thinking process. The threats may occur unexpectedly interfering with DP systems work. Uncontrolled vector of thrust from propulsion system is one of them. The possibility of detection such situation gives the opportunity of switching off, disengaging or switching on zero pitch without essential disturbing the DP operations due to redundancy. The vector control of thrust is essential for safe operation of DP systems. The systems are still improved allowing for capability increasing such systems for self-diagnostics and preventive aims. The development of thrust control systems is indicated. The role of DP operator is still important but the effects of failures in DP systems may be more mitigated.

\section{References}

[1] Global 1200 DP2 FMEA, Noble Denton Marine, Inc., 2009.

[2] Rules for Classification and Construction Ship Technology, 15, Dynamic Positioning Systems, Germanischer Lloyd, 2013.

[3] Alkan, B., Thrust Control Design for Unmanned Marine Vehicles, Izmir, 2012.

[4] Guide for Dynamic Positioning Systems, ABS, 2013.

[5] International Guidelines for The Safe Operation of Dynamically Positioned Offshore Supply Vessels, IMCA 2009.

[6] A Guide to DP Electrical Power and Control Systems, IMCA M206, 2010.

[7] Dynamic Positioning Systems - Operation Guidance, Recommended Practice DNV-RP-E307, DNV 2011.

[8] Herdzik, J., Possibilities of improving safety and reliability of ship propulsion system during DP operation, Journal of KONES, Vol. 19, No. 2. pp. 219-226, Warsaw 2012.

[9] Herdzik, J., Challenges of ship propulsion systems during DP operations, Journal of KONES, Vol. 19 No. 2. pp. 211-218, Warsaw 2012..

[10] Herdzik, J., Verifications of Thrusters Number and Orientation in Ship's Dynamic Positioning Systems, Navigation and Safety of Sea Transportation, Maritime Transport \& Shipping, pp. 159-163, 2013.

[11] Herdzik, J., Raportowanie i analiza raportów zdarzeń wypadkowych ze statków z systemami dynamicznego pozycjonowania, Logistyka, No. 6, pp. 206-211, 2013.

[12] Herdzik, J., Aspekty niezawodności systemów dynamicznego pozycjonowania statków, Logistyka, 6/2014, ISSN 1231-5478, pp. 712-717.

[13] Herdzik, J., Systemy kontroli naporu układów napędowych statków z systemami dynamicznego pozycjonowania, Logistyka, No. 3, pp. 1800-1807, CD1, 2015.

[14] Kongsberg K-Pos DP, Dynamic Positioning System, Product Description, Kongsberg, 2006.

[15] Witkowska, A., Śmierzchalski, R., Adaptive dynamic control allocation for dynamic positioning of marine vessel based on backstepping method and sequential quadratic programming, Ocean Engineering, Vol. 163, pp. 570-582, 2018.

[16] https://w3.siemens.no/home/no/no/sector/industry/marine/pages/thruster_control_systems.aspx (available 04.03.2019)]

[17] Guidelines for vessels and units with dynamic positioning (DP) systems, IMO, MSC.1/Circ.1580, 2017. 